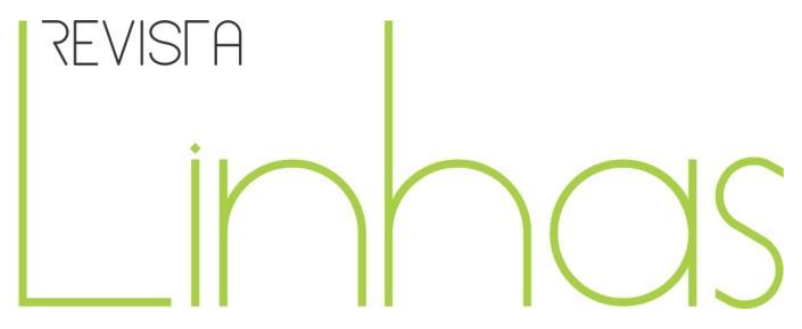

\title{
Políticas de formação continuada de professores: inovação para uso da robótica como recurso pedagógico
}

\begin{abstract}
Resumo
O presente artigo objetiva analisar políticas e experiências de formação continuada de professores para uso da robótica educacional, considerando as possibilidades de os profissionais inovarem nas práticas pedagógicas mediadas por essa tecnologia. Trata-se de uma pesquisa qualitativa, que se utiliza de análise bibliográfica, documental e pesquisa-ação. A formação continuada dos professores para o uso a robótica educacional pode beneficiar o processo de ensino e de aprendizagem, visto que articula teoria e prática. A partir do estudo, constata-se que as políticas de democratização do acesso às tecnologias têm possibilitado o desenvolvimento de propostas de formação continuada que utilizam a robótica educacional como ferramenta pedagógica em diferentes locais. Muitos professores, no entanto, não se sentem seguros para utilizá-la em sala de aula, sendo necessário atentar, no processo formativo, para as suas experiências prévias, dificuldades formativas, condições de trabalho, tempo para estudos e suporte pedagógico.
\end{abstract}

Palavras-chave: Processos de Autoformação: Formação Inicial e Continuada de Professores. Políticas Educacionais (Moderna). Robótica na Educação.

\section{Denilton Silveira de Oliveira}

Universidade Federal do Rio Grande do Norte - UFRN - Natal/RN - Brasil denilton@ufrn.edu.br

\section{Luciane Terra dos Santos Garcia}

Universidade Federal do Rio Grande do Norte - UFRN - Natal/RN - Brasil Itsgarcia@gmail.com

\section{Luiz Marcos Garcia Gonçalves} Universidade Federal do Rio Grande do Norte - UFRN - Natal/RN - Brasil Imarcos@dca.ufrn.br

\section{Para citar este artigo:}

OLIVEIRA, Denilton Silveira; GARCIA, Luciane Terra dos Santos; GONÇALVES, Luiz Marcos Garcia. Políticas de formação continuada de professores: inovação para uso da robótica como recurso pedagógico. Revista Linhas. Florianópolis, v. 20, n. 43, p. 102-131, maio/ago. 2019. 


\title{
Teacher continued training policies: innovation for the use of robotics as a pedagogical resource
}

\begin{abstract}
This article aims to analyze policies and experiences of continuing teacher education for the use of educational robotics, considering the possibilities of professionals to innovate in pedagogical practices mediated by this technology. This is a qualitative research, which uses bibliographical, documentary, and action-research. The continuing education of teachers for use of educational robotics can benefit the teaching and learning process, since this methodology articulates theory and practice. From this study, it can be seen that the policies for democratization of the access to technologies have made possible the development of proposals for continuing education that use educational robotics as a pedagogical tool, in different places. Many teachers, however, do not feel comfortable to use it in the classroom, and it is necessary to take into account, in the training process, their previous experiences, training difficulties, working conditions, time for studies and pedagogical support.
\end{abstract}

Keywords: Processes of Self-Formation: Initial and Continued Formation of Teachers. Educational Policies (Modern). Robotics in Education. 


\section{Introdução}

Crescentemente, tem sido enfatizado o uso de tecnologias educacionais nas escolas, visando fomentar inovações nas práticas pedagógicas atendendo a interesses mercantis de formação de capital humano. As ferramentas tecnológicas no ensino, no entanto, podem ser empregadas de forma diversificada, atendendo tanto a esses interesses, quanto se colocando a serviço da promoção de formação integral, levando em consideração os objetivos que orientam sua utilização.

A Robótica Educacional pode ser entendida como instrumento de auxílio à aprendizagem ou como objeto de estudo, ou seja, a robótica, propriamente dita. Configura um ambiente de trabalho no qual os alunos podem construir ou montar um protótipo de robô, bem como programá-lo, recorrendo ao computador. Essas tarefas são desenvolvidas para atender a objetivos de ensino e de aprendizagem, como parte de um conjunto de procedimentos e técnicas, envolvendo o objeto robô (SILVA, 2008), que possibilita articular conhecimentos de diversas áreas.

Sua utilização, na escola, tem sido impulsionada com base em setores distintos da sociedade, com vieses diferentes. De um lado, a denominada Indústria 4.0, que atua por meio de empresas, utilizando tecnologias inovadoras, com fábricas totalmente robotizadas e integradas à tecnologia de comunicação e produção digital, permitindo alto controle de sua produção, em todas as suas fases. A implementação da Indústria 4.0 tem carência de mão de obra com alta qualificação, com conhecimentos de robótica. Visando auxiliar esse processo, ações fomentadas por organismos, como o Serviço Social da Indústria (SESI), têm buscado preparar pessoas em condições de enfrentar os desafios dessa indústria, com o ensino de robótica e mediante competições (SESI, 2019).

Em um outro viés de inserção da RE no processo educativo, sua utilização pode ser vislumbrada como mais uma possibilidade de se enfrentar o problema da exclusão digital e social, bem como de atrair pessoas, principalmente as mulheres, para os cursos universitários com cunho mais tecnológico. Esse tem sido um papel desempenhado por algumas universidades por meio do fomento às competições de robótica (AROCA et al., 2016) e de projetos de extensão (ARANIBAR et al., 2006; MINAMI et al., 2018; SÁ, 2009;). Nesse sentido, visando, ainda, formar futuros estudantes, professores universitários de 
todo o Brasil vêm contribuindo para inserir a Robótica Educacional no currículo escolar desde as séries iniciais da Educação Básica, seja por meio da formação de alunos, incluindo projetos de extensão, seja de professores, visando colaborar com o processo ensino-aprendizagem.

Finalmente e muito recentemente, os gestores e profissionais da Educação Básica (pública e privada) passaram a vislumbrar a RE como uma tecnologia educacional eficaz, para ser usada, efetivamente na escola e colaborar no processo ensino-aprendizagem. É consensual que, utilizando a RE, como ferramenta de ensino de forma adequada, o aluno pode aprender conteúdos de qualquer componente curricular da Educação Básica, sendo de grande auxílio ao professor no ensino de conteúdos que, particularmente, possam parecer sem interesse para determinados grupos de aluno (SILVA, 2008).

Independentemente do viés, é notório que a Robótica Educacional consiste em um recurso pedagógico que oferece proposta lúdica e criativa, para trabalhar conteúdos curriculares diversos, em todos os níveis de ensino, podendo colaborar para a melhoria da qualidade educacional visto que estimula a interdisciplinaridade, a autonomia dos estudantes, a motivação para o estudo, o trabalho em grupo de forma colaborativa, a resolução de problemas. Ademais, promove o desenvolvimento da concentração, da observação seletiva, do raciocínio lógico-matemático, da autoconfiança, entre outras características, que a colocam como importante ferramenta de inovação pedagógica.

Objetiva-se, assim, fazer uma síntese sobre o panorama atual das políticas de formação continuada de professores para o uso das tecnologias educacionais, em particular, da Robótica Educacional, bem como apresentar alguns projetos que foram desenvolvidos em São Paulo, São Carlos, Ponta Porã e João Pessoa. Ainda é objetivo apresentar e discutir as especificidades de um projeto desenvolvido, a título de pesquisaação, em parceria com escolas públicas municipais do Rio Grande do Norte. Por fim, traçar um direcionamento, tecendo-se comentários e discussões acerca das ideias e princípios básicos das políticas que devem nortear a implementação da RE, considerando as possibilidades de os profissionais inovarem nas práticas pedagógicas mediadas por essa tecnologia. 


\section{Políticas de formação continuada de professores para uso de tecnologias com foco na robótica educacional}

A formação inicial e continuada do professor consiste em uma prioridade para a melhoria na qualidade da educação (MOURA; SOUSA, 2016; OLIVEIRA et al, 2017). Isso se torna particularmente significativo com o advento das Tecnologias Digitais (TD), aplicadas à educação, uma vez que grande parte de seus profissionais são migrantes digitais, ou seja, pessoas nascidas em meio a uma cultura analógica e que, em grande medida, não possuem fluência tecnológica, para atuar no contexto da cultura digital, a qual a maioria dos estudantes domina e não há como imaginá-los fora dela (SCHLEMMER, 2006). A conquista que advém da mudança de paradigma da cultura analógica para a digital, recai sobre a possibilidade de cada indivíduo ser produtor ativo de conteúdos e não mais, apenas, consumidor passivo, como ocorria no mundo com os meios analógicos. Isso implica, porém, o domínio de ferramentas e tecnologias para lidar com conteúdos digitais que, ainda, não se encontram acessíveis à grande parte da população do país.

Nessas condições, muitos estudantes e professores das escolas públicas brasileiras, até agora, não interagem em rede, tampouco utilizam tecnologias educacionais, de forma significativa, tendo em vista favorecer ou dinamizar os processos de ensino e de aprendizagem. Muitos fatores contribuem para isso; entre os quais, é possível apontar o número reduzido de equipes de formadores; baixa disponibilidade de material didático e equipamentos tecnológicos; tempo insuficiente para os professores investirem em formação continuada; acompanhamento incipiente das ações; falta de incentivo da equipe gestora da rede de ensino e da escola; fraca infraestrutura logística, elétrica e de mobiliário dos laboratórios; baixa qualidade da conexão à internet, entre outros aspectos.

Ao se pensar nas tecnologias aplicadas à educação, conforme Kenski (2007), a preocupação recai sobre os conhecimentos requeridos dos atores envolvidos no processo educativo (professores, alunos e gestores), com ênfase no uso das tecnologias como alternativa aos modelos tradicionais de educação. Cabe ao professor contextualizar e imprimir sentido ao uso dessas tecnologias visando subsidiar os processos de ensino e de aprendizagem. Esse profissional encontra dificuldades para alcançar o intento, visto 
que, grande parte sequer entendeu as consequências da transformação de paradigma dos meios analógicos para os meios digitais na sociedade e, em especial, na educação.

É importante que os professores desenvolvam práticas pedagógicas com o uso das tecnologias. Mas não podem, entretanto, ser responsabilizados, única e exclusivamente, por esse uso, sem que lhes sejam oferecidas as condições intelectuais, materiais e psicológicas, necessárias à construção dos saberes requeridos. A utilização de tecnologias em sala de aula pode contribuir, entre outras ações, para a melhoria da qualidade educacional, sendo, portanto, imprescindível que lhes sejam oferecidas as bases de sustentação para que os professores inovem em suas práticas pedagógicas, fazendo uso delas. Isso requer a consolidação de políticas de formação inicial e continuada de professores em tecnologias educacionais e programas que contribuam para democratizar o acesso a essas tecnologias.

Deve-se reconhecer, em um contexto de hegemonia do Estado mínimo neoliberal, a necessidade de cortar investimentos na área social, entre outras formas, barateando o custo da formação da força de trabalho, reduzindo o nível de conhecimento a que tem acesso. Nesses moldes, conforme observam Moura e Sousa (2016, p. 130), a política de formação de professores, implementada no país "não necessariamente está baseada nos conhecimentos exigidos para a construção e avanço de um projeto político-pedagógico, pautado por uma concepção de educação socialmente referenciada". Assim, a coexistência de projetos educacionais conflitantes na sociedade é manifestada por meio de posicionamentos contraditórios que orientam as políticas e os programas educacionais, denotando avanços e recuos nas concepções e nos investimentos realizados na formação continuada dos professores, em particular, daqueles que atuam com as tecnologias educacionais.

A formação de professores, para o uso de tecnologias educacionais, teve impulso, na década de 1990 por meio do Programa Nacional de Tecnologias na Educação (Prolnfo), criado pela Portaria n 522/MEC, de 9 de abril de 1997. As ações do Prolnfo possibilitaram investimentos na compra de equipamentos (computadores, projetores multimídia, notebooks, tablets, entre outros), visando garantir a inclusão digital da comunidade escolar. Essas aquisições, no entanto, foram insuficientes para atender à demanda do país. 
Além disso, constata-se falta de sincronia entre as ações destinadas à aquisição de equipamentos e à formação do professor para seu uso pedagógico. O atraso de, aproximadamente, oito anos entre uma ação e outra comprometeu a melhoria da qualidade educacional pela utilização das tecnologias educacionais. Muitas escolas que receberam laboratórios de informática, praticamente não os utilizaram porque os professores não se sentiam seguros para fazê-lo. A garantia do acesso e domínio das tecnologias educacionais, como um direito, em particular, dos estudantes da rede pública de ensino, vem sendo adiado e, em grande medida, ainda não está assegurado.

Críticos das políticas do Proinfo, mediante a constatação de seus resultados limitados, questionaram a eficácia do uso das tecnologias na educação. O mal-estar, decorrente da crise de identidade do professor, migrante digital, nascido em meio a uma cultura analógica e, agora, obrigado a atuar em um contexto novo, reforçou e deu sentido a essas críticas. Muitos professores que não foram, devidamente e, em tempo hábil, capacitados para o uso das tecnologias, desenvolveram resistência a elas, passando a vêlas como ameaças, quando deveriam ser encaradas como aliadas.

Em 2007, com a reformulação do Proinfo, e a criação do Proinfo Integrado, programa do MEC destinado ao desenvolvimento de políticas públicas voltadas ao uso pedagógico de Tecnologias da Informação e Comunicação no âmbito da Educação Básica, políticas mais concretas começaram a ser implementadas. Um exemplo dessa mudança foi o lançamento do projeto do MEC Um Computador Por Aluno, ProUCA', cujo objetivo foi promover a inclusão digital e pedagógica de estudantes e professores, impulsionando a sua formação continuada.

$\mathrm{Na}$ perspectiva de dinamizar a colaboração entre os entes federados na consecução da qualidade educacional, foi lançado, no segundo governo de Luiz Inácio Lula da Silva (2007-2010), o Plano de Desenvolvimento da Educação (BRASIL, 2007). Esse plano trazia a proposta de planificação de ações da Educação Básica, por meio de contratos de gestão firmados entre os entes federados. A adesão ao Plano de Metas

\footnotetext{
${ }^{1}$ O Prouca foi inspirado no projeto "One Laptop per Child", OLPC, conduzido pelo MIT (Massachusetts Institute of Technology). No Brasil, em 2007, foram selecionadas inicialmente cinco escolas para um projeto piloto e com o resultado dessa experiência, mais trezentas escolas foram convidadas a participar do projeto. Trata-se da distribuição de um laptop a professores e alunos, com programas educativos, jogos, editor de texto, comunicador instantâneo, criação e edição de áudio, vídeo e fotos. Gerenciado com sistema operacional Linux, que adota uma licença livre e aberta (CARVALHO; ALVES 2011).
} 
Compromisso Todos pela Educação, por meio de termo assinado pelos entes federados, previa a consecução de metas de qualidade educacional e a elaboração do Plano de Ações Articuladas (PAR). Esse plano aliava a análise situacional da rede de ensino com o planejamento de ações, em diferentes eixos, entre os quais a formação inicial e continuada de professores.

Para facilitar as ações a serem implementadas pelos entes federados, em 2008, foi publicado o Guia de Tecnologias Educacionais, por meio do qual o MEC oferecia, aos sistemas de ensino, uma ferramenta que os auxiliasse na decisão sobre a aquisição de materiais e tecnologias para uso nas escolas brasileiras de educação básica (BRASIL, 2008). Esse guia, entre outras ações, denota a amplitude das parcerias público-privadas no âmbito educacional, em que o MEC compra serviços prestados por empresas, a serem implementados nas instituições educativas públicas, ressaltando, assim, o crescimento das políticas de quase-mercado educacional.

Os Guias de Tecnologias Educacionais, produzidos pelo MEC nos anos de 2008 (BRASIL, 2008) e 2011, apresentam, nos blocos denominados Ensino e Aprendizagem, entre outras tecnologias, kits de robótica educacional, fornecidos por empresas privadas, para serem usados no ensino dos conteúdos curriculares da educação básica (BRASIL, 2011). Apesar de não serem soluções baratas, o fato de os kits de robótica educacional serem ali apresentados, tornou essa ferramenta pedagógica, bem como a formação para o seu uso, acessível às escolas públicas.

Tendo em vista facilitar o processo de compra, no início de 2018, o MEC lançou um edital de Pregão Eletrônico para Registro de Preços $n^{\circ}$ 04/2018 (BRASIL, 2018), objetivando normatizar a aquisição de kits de robótica educacional. O edital impunha, como condição aos concorrentes, a apresentação do equipamento em si (os kits de robótica) acompanhado de material de apoio pedagógico (guia de tecnologia) tanto para alunos, quanto para professores, em versão impressa e digital (BRASIL, 2018). Deveriam ser apresentadas, ainda, sugestões de atividades práticas para a realização de trabalho multidisciplinar, em concordância com as Diretrizes Curriculares Nacionais da Educação Básica (DCNEB), para cada etapa da escolaridade básica, ano/turma e faixa etária dos alunos. O material deveria propor situações-problemas; sugestão de montagens dos sistemas robóticos passo a passo, em diferentes níveis, ampliando a quantidade de 
recursos disponíveis a cada mudança de nível; informações sobre tecnologias; e outras atividades (BRASIL, 2018).

Cabe ressaltar que o guia de tecnologia deveria atender aos critérios de avaliação previstos no art. 11, do Decreto n 9.099, de 18 de julho de 2017 (BRASIL, 2017). Esse artigo prevê que a etapa de avaliação pedagógica contará com comissão técnica específica, integrada por equipes formadas por professores das redes públicas e privadas de ensino superior e da Educação Básica, responsável por emitir parecer com apreciação do produto.

Entre as condições para participação na disputa, encontra-se o oferecimento de formação continuada do professor em robótica educacional, na modalidade a distância, conduzida pela empresa vencedora da licitação. Essa exigência está de acordo com a Lei $\mathrm{n}^{\circ}$ 12.056, de 13 de outubro de 2009 (BRASIL, 2009), que alterou o art. 62 da Lei de Diretrizes e Bases da Educação Nacional, Lei $n^{\circ}$ 9.397, de 20 de dezembro de 1996. Os parágrafos segundo e terceiro do referido artigo, respectivamente, determinam que a formação continuada e a capacitação dos professores em serviço podem ocorrer a distância, enquanto a formação inicial deve ser, preferencialmente, presencial, podendo ser subsidiada por recursos e tecnologias próprios da modalidade a distância.

A proposta seria usar o ambiente e-Proinfo do MEC, que permite a criação de Ambiente Virtual de Aprendizagem (AVA), e, nele, seriam disponibilizados os recursos didáticos (manuais, textos, apostilas, vídeos, áudios) necessários à formação. Deveriam ser inseridas as ferramentas de interação (fórum, chat, etc.), permitindo a troca de conhecimentos entre os professores formadores e os cursistas. Cada empresa concorrente teria que propor o curso, definindo carga horária e metodologia adequada à formação, considerando as turmas e seus respectivos professores (BRASIL, 2018). Convém destacar que, dessa carga horária e metodologias dependerão, em grande medida, a segurança do professor em utilizar a nova ferramenta em sala de aula, considerando as diferenças individuais.

As ferramentas de interação digitais são úteis tanto para que professores e estudantes apreendam os conteúdos de formação quanto para a consolidação da aprendizagem, que requer utilização efetiva e suporte pedagógico. Assim, é importante garantir espaços para que os sujeitos compartilhem experiências, dúvidas e soluções, 
decorrentes da formação; registrem conhecimentos construídos, para que experiências possam ser refeitas, modificadas e/ou ampliadas com menos esforço por parte daqueles que se lançam aos novos ensaios. As ferramentas de interação digitais propiciam esse compartilhamento, em particular, por meio de fóruns e chats.

Além disso, essas ferramentas viabilizam a socialização de conhecimentos, angústias e conquistas, possibilitando suporte emocional necessário àqueles que vivenciam momentos de instabilidade, próprios de quem empreende novas experiências. Conforme experiências anteriores, determinados cursistas poderão apresentar maior facilidade do uso da robótica educacional, enquanto outros não prescindem de suporte pedagógico, técnico e emocional, para inovar nas práticas pedagógicas com o uso da robótica educacional. Nesse sentido, ao se pensar um curso de formação continuada, é importante prever, na carga horária do curso, tempo para esse suporte.

Todo o material didático usado na formação deveria ser objeto da licença CreativeCommons (Atribuição Não-Comercial, disposta no texto legal disponível em <https://creativecommons.org/licenses/by-nc/4.o/deed.pt_BR>), ou ser acompanhado de uma declaração, por meio da qual o detentor do direito patrimonial autoriza a disponibilização do conteúdo e/ou material a terceiros, de forma gratuita (sem finalidade lucrativa), incluindo a permissão para a criação de obras derivadas a partir dos mesmos, desde que citada a autoria. Todos os conteúdos disponibilizados no material de apoio pedagógico deveriam passar por avaliação prévia do MEC, conforme estabelecido na primeira etapa (BRASIL, 2018).

Quanto ao conteúdo do curso, o edital define que sejam incluídos: conceitos de robótica e de robótica aplicada à educação; exploração do kit de Robótica Educacional; exploração do software de programação; construção de protótipos e robôs; conceitos básicos sobre atuadores e sensores; conceitos básicos de programação; design e tecnologia, ciências e matemática. O curso seria apresentado por meio de recursos estáticos e dinâmicos como: som (voz humana, música, efeitos especiais), fotografia (imagem estática), vídeo (imagens em pleno movimento), animação, gráfico, texto (incluindo números, tabelas, etc.). Por fim, deveria estar acessível para multiplataformas (Linux Educacional, Windows, Android, iOS e Mac OS), bem como operar nos navegadores Internet Explorer, Safari, Google Chrome e FireFox (BRASIL, 2018). 
A formação dos professores deveria apresentar os seguintes módulos: 1Introdutório; 2- Aspectos técnicos e pedagógicos da robótica educacional. Ao final de cada módulo, haveria atividades avaliativas para o educador testar seus conhecimentos acerca dos conteúdos dos módulos. A formação deveria atingir os seguintes objetivos: inserir novas tecnologias na prática do educador; promover plena utilização dos kits de robótica educacional; promover o ensino de conteúdos curriculares por meio da Robótica Educacional; e maximizar a utilização das soluções que foram fornecidas (BRASIL, 2018).

As atividades previstas se referem não só à formação de conhecimentos técnicos para o trabalho com a Robótica Educacional, mas, também, assinala como um ponto positivo da proposta, a ênfase no uso da ferramenta para o ensino dos diversos conteúdos curriculares. Por outro lado, não enfatiza como seria o suporte prestado para a consecução das atividades no cotidiano escolar, ou seja, se haveria chats e fóruns durante determinado espaço de tempo de consolidação da proposta nas escolas.

Cabe ressaltar que o Pregão Eletrônico para Registro de Preços, $n^{\circ}$ 04/2018 (BRASIL, 2018), encontra-se suspenso por decisão judicial impetrada por empresa concorrente no pleito, visto que não havia obtido boa avaliação em sua proposta; desse modo, o pregão não tem previsão de retomada. Entende-se que o processo de judicialização das relações sociais vivenciado no país, especialmente, a partir da década de 1990, se, por um lado, denota maior facilidade de acesso ao poder judiciário (MOURA; SOUSA, 2016), por outro, dificulta, atrasa ou impede ações que poderiam impulsionar melhorias nos serviços educacionais públicos, tendo em vista atender a interesses particulares. Considerando que essa é uma política pública que, ainda, não se concretizou, não se pode avaliar seus impactos educacionais.

Mudanças paulatinas, no entanto, vêm aumentando o acesso dos estudantes e professores aos laboratórios de informática, às redes de comunicação, bem como dinamizando e facilitando a aquisição de kits de Robótica Educacional, no âmbito da educação pública. Isso tem desencadeado experiências de formação de professores em Robótica Educacional, impulsionadas, quer por projetos das secretarias de educação, quer pela atuação de empresas que anseiam vender seus produtos, assim como por pesquisadores que acreditam no potencial da Robótica Educacional como inovação pedagógica capaz de influenciar a qualidade educacional. Cabe, por conseguinte, discutir 
como a formação continuada de professores em nessa área pode colaborar para a inovação pedagógica.

\section{Inovação pedagógica e formação continuada para uso da robótica educacional}

Pode-se entender um robô como um dispositivo que realiza ações complexas de forma autônoma, reagindo às variações do ambiente, conforme definido em sua programação, sem a intervenção direta do homem (SILVA, 2008). Para tanto, segundo Mataric (2014), o robô necessita de sensores para detectar alterações no ambiente (luz, relevo, textura, cor, vibrações sonoras) e agir sobre ele, visando alcançar os objetivos para o qual foi programado ou, eventualmente, responder a alterações providas pelo ambiente.

A Robótica Educacional ou pedagógica refere-se, segundo Araújo e Mafra (2015), à utilização de sistema robótico composto de hardware (componente físico do sistema no qual é empregado material comprado ou de sucata ou kits de montagem) e o software (componente lógico do sistema usado para controlar o robô) em ambiente pedagógico de interação entre professor e estudante. O processo de ensino e de aprendizagem mediado pelo robô visa construir conhecimentos em diversas áreas do conhecimento, podendo ser empregado nos diferentes níveis e etapas de ensino.

Na concepção de Vygotsky (2007), cultura e sociedade são forças geradoras da produção mental, do raciocínio e do pensamento lógico, que possibilitam o desenvolvimento de funções psicológicas superiores, diferenciando o homem de outras espécies. A relação humana com o mundo é mediada por artefatos e pessoas que possibilitam o desenvolvimento desses processos mentais. Nessa lógica, a Robótica Educacional constitui-se em mecanismo de mediação, capaz de auxiliar o professor no ensino dos conteúdos curriculares, tendo em vista o desenvolvimento das funções mentais do estudante. Assim, cabe a ele propor problemas, em conformidade com a área potencial de desenvolvimento do educando, que, por sua vez, deve superar desafios,

utilizando o robô como instrumento de aprendizagem, considerando a orientação do adulto e a colaboração dos pares. 
Atividades desse tipo facultam maior envolvimento do educando e, segundo Abreu (1995), promovem ambiente de ensino e de aprendizagem no qual os estudantes demostram ser mais criativos, inventivos e responsáveis pela própria aprendizagem. Esse recurso possibilita que conceitos da Matemática, Física, Computação, sejam aplicados de forma concreta, facilitando sua compreensão e articulação a outros conteúdos, provenientes das demais áreas da ciência, que comporão os desafios de aprendizagem. Por meio da Robótica Educacional, é possível integrar conteúdos de diferentes áreas do conhecimento; possibilitar a construção do raciocínio lógico-matemático; propiciar a superação de desafios, o respeito às diferenças, a valorização do trabalho coletivo, a construção da consciência crítica, entre outros aspectos, que, em grande medida, promovem a superação do paradigma tradicional de educação que tem marcado a atuação de muitos profissionais.

Um trabalho desse tipo pode demandar de determinados profissionais mudança de concepções pedagógicas bem como aprendizagem de conteúdo específico que, para muitos, requer processo formativo. Carbonell (2002, p. 19) define a inovação pedagógica como sendo "[...] um conjunto de intervenções, decisões e processos, com certo grau de intencionalidade e sistematização". A inovação pode se associar à mudança e à melhoria das práticas pedagógicas tendo em vista renovar "atitudes, ideias, culturas, conteúdos, modelos e práticas pedagógicas" (CARBONELL, 2002, p. 19). Cabe destacar que nem todo processo inovador origina mudanças, tampouco implica melhoria, visto que a inovação se refere à introdução de algo novo em determinado contexto; isso nem sempre gera mudanças qualitativas nas práticas e nas concepções dos sujeitos.

A inovação consiste no primeiro momento da construção de mudanças; a partir daí, é possível ao sujeito “mudar a visão que orienta seu modo de agir, de pensar e de interagir com as coisas ao seu redor e com os outros. Enfim, mudar o modo de atribuir sentido à prática" (FARIAS, 2006, p. 42). Os sujeitos constroem mudanças, segundo Farias (2006, p. 56), na medida em que mobilizam "[...] capacidades cognitivas e afetivas diversas, se relacionam com as inovações e constroem respostas para enfrentar as demandas emergentes, as quais têm um significado, imprimindo um sentido à mudança projetada". 
Nesse sentido, um processo de inovação pedagógica pode colaborar para que se modifiquem hábitos, rotinas, à medida que novos sentidos para a ação são criados. $\mathrm{A}$ formação continuada em robótica educacional pode, por conseguinte, desencadear processos de inovação, conduzindo mudanças nas práticas pedagógicas. No entanto, essa não é uma tarefa fácil, pois, segundo Thurler (2007), a escola constitui-se em uma instituição estável, capaz de sobreviver a mudanças que afetam sua missão, recursos, a renovação permanente do quadro discente e até de docentes e gestores.

Para Thurler (2007, p. 25), a estabilidade das relações escolares "é positiva no sentido de garantir sua coerência e a continuidade de sua ação coletiva e das práticas pedagógicas individualizadas", entretanto, quando se torna a lógica dominante da estrutura organizacional, pode produzir rigidez, com forte prejuízo à qualidade do ensino e da aprendizagem. A escola precisa preservar certo nível de estabilidade, sem, entretanto, negar novas práticas que colaborem na consecução de sua função social.

Para inovar, portanto, o profissional precisa estar convencido da sua importância, pois, segundo Thurler (2007, p. 18), “desde a infância, desenvolvemos a arte de pesar os prós e os contra e a hesitar entre o status quo e a mudança”. Isso porque a decisão não é fácil, "supõem novas aprendizagens, riscos de fracasso, uma perda provisória de rotinas e de referências, o luto de certos hábitos, uma fase de mínima eficiência" (THURLER, 2007, p. 18).

Pela insegurança que o processo inovador proporciona, muitos profissionais têm dificuldades em empreendê-lo. Quanto mais complexas as atividades e as ferramentas pedagógicas inseridas na prática docente, a exemplo da Robótica Educacional, mais sofisticados os raciocínios requeridos, exigindo tempo e esforço para utilizar a ferramenta com qualidade. Por isso, reitera-se a defesa de que uma formação continuada em Robótica Educacional precisa reservar não só tempo para estudo acerca do uso da ferramenta, mas também para reflexão sobre a ação, articulação entre teoria e prática, e, ainda, o suporte pedagógico e emocional para consolidação das ações. Não considerar esses fatores pode fazer com que vultosos investimentos, destinados à melhoria da prática pedagógica, não alcancem resultados significativos.

Cada professor responderá, de forma particular, à demanda por inovação fazendo uso de sua autonomia e capacidade para abraçar ou resistir a elas. Assim, a sobrecarga de 
atribuições e a extensa carga horária de trabalho a que a maioria dos docentes se submete, bem como a pouca familiaridade e as dificuldades de acesso às tecnologias educacionais, podem torná-lo indisponível ao trabalho pedagógico com a robótica pedagógica, mesmo que conheça seus benefícios.

De qualquer forma, propor inovações sem atentar para as condições preexistentes pode comprometer os resultados esperados. Por isso, Thurler (2007, p. 21) demonstra que é importante "compreender onde e como os professores constroem o sentido de uma mudança proposta, individual e coletivamente, para estabelecer estruturas de aceitação favoráveis à inovação bem antes que seu conteúdo seja determinado". São os profissionais que conferem sentido às inovações, e esses sentidos precisam ser construídos coletivamente. Por isso, Alonso (2008) considera que a incorporação de um projeto que reorganiza o trabalho escolar precisa ser discutido coletivamente, e estar contemplado no projeto político-pedagógico da escola.

O uso da Robótica Educacional, como recurso pedagógico usado na mediação do processo de ensino-aprendizagem, no contexto da rede pública de educação, embora promissor na promoção da qualidade da educação, encontra dificuldades que precisam ser superadas, entre as quais, a formação do professor. Existem experiências de formação profissional em andamento em diversas regiões do país, apresentadas a seguir, considerando o fato de que se tem possibilitado a inovação na prática pedagógica do professor.

\section{4. formação continuada de professores em robótica educacional: uma síntese de experiências inovadoras}

Compreende-se a Robótica Educacional como tecnologia capaz de potencializar o trabalho do professor na formação integral do estudante (SILVA, 2008). Entretanto, sua utilização como recurso pedagógico mediador, implica que os profissionais conheçam seu potencial e saibam utilizá-lo. Convencidas da importância desse recurso, determinadas redes públicas de ensino têm financiado formações continuadas para os professores, bem como pesquisadores da área tecnológica têm promovido formações visando à democratização de experiências nas redes públicas de educação do país. 
Buscando maior compreensão acerca das experiências de formação de professores em Robótica Educacional implementadas no país, este artigo mostra uma síntese de algumas dessas experiências, encontradas nos anais do Workshop de Robótica Educacional (GONÇALVES, 2008-2018) que reúne trabalhos desenvolvidos sobre o assunto. Consideram-se os artigos publicados e as informações compiladas com base nas palestras convidadas desse evento, apresentadas em 2017 e 2018, abordando a formação dos profissionais em Ponta Porã e João Pessoa, cujos dados foram complementados com dados coletados nos sites das respectivas secretarias de educação.

\subsection{A experiência de João Pessoa}

A Secretaria Municipal de Educação de João Pessoa tem desenvolvido projeto de ensino com uso da Robótica Educacional, cujos resultados expressivos vêm sendo apresentados em eventos e competições da área. Atualmente, a prefeitura de João Pessoa é considerada referência nacional no desenvolvimento desses projetos, de forma que representantes do MEC e do Fundo Nacional de Desenvolvimento da Educação têm visitado as escolas da Rede Municipal de Ensino para conhecer as experiências desenvolvidas com a Robótica Educacional (JOÃO PESSOA, 2017).

Conforme Ribeiro (2018), o trabalho com o ensino da Robótica Educacional na Paraíba teve impulso a partir de 2014. A empresa Pete, de São Carlos (São Paulo), tanto vendeu a solução tecnológica de robótica educacional (kits de robótica Alpha), quanto se incumbiu de prover a formação dos professores (JOÃO PESSOA, 2017). Na ocasião, foram capacitados 63 professores de salas de aula, de 37 escolas municipais da rede pública.

O curso de formação continuada de professores contou com carga horária de 40 horas presenciais, mais oito horas de formação a distância e outras oito horas para o desenvolvimento de um projeto a ser realizado em grupo. A carga horária do curso, por conseguinte, aborda tanto a formação teórico-prática acerca do uso da ferramenta, quanto o tempo de interação para que os professores apliquem os conhecimentos construídos, por meio de projetos. Isso consiste em determinado suporte para que os profissionais pudessem inovar no seu trabalho pedagógico utilizando a ferramenta em apreço. 
Em determinadas escolas, inclusive as localizadas em regiões carentes, a formação oferecida aos professores possibilitou a continuidade do trabalho nas escolas. Os impactos dessa iniciativa foram apresentados na palestra de abertura do IX Workshop de Robótica Educacional (WRE, em novembro de 2018), realizado em João Pessoa (Paraíba), onde representantes da secretaria de educação, professores da rede de ensino e estudantes apresentaram a experiência municipal numa palestra coletiva.

Na ocasião, ficou, também, evidente, que muitos profissionais não prosseguiram com a experiência em sala de aula (RIBEIRO, 2018). A continuidade do projeto foi garantida tanto pela contratação de estudantes de cursos de graduação da área tecnológica, das universidades locais, quanto por egressos das próprias escolas que se sobressaíram no trabalho com a Robótica Educacional. A Secretaria Municipal de Educação organizou-se para prestar o necessário suporte pedagógico aos monitores no planejamento e implementação de projetos pedagógicos que utilizam a robótica como ferramenta educativa (RIBEIRO, 2018).

A não continuidade do trabalho por parte de muitos professores da rede educacional de João Pessoa suscita a realização de pesquisas acerca das condições oferecidas para a inovação de sua prática pedagógica. A atuação dos monitores garante a continuidade do trabalho nos laboratórios de informática da rede, no entanto, em certa medida, compromete o potencial pedagógico do uso da ferramenta pelo professor no processo de ensino e aprendizagem de conteúdos curriculares trabalhados na sala de aula.

\subsection{A experiência de São Carlos}

Outro projeto envolvendo formação de professores para o uso de robótica foi desenvolvido com quatro professoras em uma escola da rede pública de São Carlos (São Paulo), no ano de 2014 (GUIMARÃES; PERALTA; PRADO, 2014). Os princípios habermasianos do Agir Comunicativo foram usados para conduzir esse processo formativo, objetivando a prática de ensino e de avaliação com uso da robótica em sala de aula. Esse trabalho foi desenvolvido por pesquisadores da Universidade Estadual Paulista (UNESP), sendo, um deles, representante da empresa Pete Educação com Tecnologia, que oferece soluções de hardware e software para o ensino da Robótica Educacional. 
O estudo não tem foco nos aspectos metodológicos da experiência formativa, com relação à duração, à carga horária, ao acompanhamento das ações de pós-formação ou, ainda, quanto ao material didático empregado. Seu objetivo foi apresentar e avaliar a adoção da Teoria da Ação Comunicativa (TAC), como arcabouço teórico, para implementar uma proposta de formação docente. Segundo Guimarães; Peralta; Prado et al. (2014, p. 61):

Tal proposta está ancorada na hipótese de que para ser efetivo um modelo de formação de professores, para o uso de robótica na escola, deve ser pautado nos ideais de professores capazes de falar e agir, de compreender as situações em que ocorrem as interações em sala de aula, coordenar suas ações didáticas, ou seja, tendo o professor como protagonista de sua própria formação.

Essa experiência, portanto, buscou conferir centralidade ao professor em seu processo de formação e "constatou que a robótica é um recurso capaz de alterar a prática pedagógica de acordo com objetivos de ensino e em função das necessidades dos alunos" (GUIMARÃES, PERALTA; PRADO, 2014, p. 60), especialmente, quando essa formação não fica circunscrita ao ensino de procedimentos meramente técnicos ou instrumentais, muitas vezes, desvinculado da prática docente, com suas múltiplas variáveis. O domínio do uso desse recurso se consolida na mediação do processo de ensino-aprendizagem dos conteúdos curriculares, no cotidiano da sala.

Com base no projeto de robótica de São Carlos, discutiram-se as necessidades formativas para a implementação da robótica como prática pedagógica dos docentes da Educação Básica. A conclusão apontada foi “[...] que a adoção do uso de robótica é facilitada quando a formação dos professores prioriza aspectos conceituais da tecnologia como prática social" (PERALTA, 2015, p. 111). Ou seja, entre as preocupações formativas envolvendo os professores para o uso de robótica nas escolas, é aconselhável uma formação menos centrada em aspectos técnicos. Aspectos filosóficos e sociológicos que envolvam a robótica produzem um efetivo envolvimento emocional e motivacional dos professores que, em geral, sentem uma grande dificuldade em lidar com conceitos e técnicas. 


\subsection{A experiência de Mato Grosso do Sul}

O trabalho de Batista et al. (2016) apresenta o crescimento histórico da robótica educacional no estado do Mato Grosso do Sul, descrevendo um conjunto de ações iniciadas na cidade de Ponta Porã, por meio do Programa NERDS da Fronteira (Núcleo Educacional de Robótica e Desenvolvimento de Software). As ações de democratização da Robótica Pedagógica no estado têm sido desenvolvidas por pesquisadores universitários em parceria com os Núcleos de Tecnologias Educacionais da rede pública de ensino. Entre as ações desenvolvidas, encontram-se: a realização de palestras para a comunidade; a preparação de estudantes para fazer parte de competições da área; e, ainda, a formação dos Professores Gerenciadores das Salas de Tecnologia (PROGETEC) para lidar com a Robótica Educacional.

A formação dos professores regentes dos laboratórios escolares consiste na realização de oficinas em que são apresentadas ferramentas de programação e de robótica. As oficinas são semipresenciais com "auxílio do AVA (Ambiente Virtual de Aprendizagem) e grupos em redes sociais" (BATISTA, et al. 2016, não paginado). Não são apresentadas informações quanto à duração do curso, material didático utilizado ou acompanhamento posterior de resultados.

Por meio de oficinas, colabora-se para que os profissionais demonstrem a aplicabilidade dos conteúdos de ensino aos estudantes; desenvolvam projetos pedagógicos que possibilitem às crianças e jovens aprenderem a programar; fomentem a participação nas olimpíadas de robótica educacional. O aumento da representação do Estado, nos eventos da OBI e OBR, através da formação de equipes de alunos para participar dessas competições, se constituía no objetivo maior da experiência (BATISTA et al. 2016).

A formação, por conseguinte, não objetiva subsidiar o trabalho pedagógico de qualquer professor no trato dos conteúdos curriculares desenvolvidos em sala de aula. Dirige-se a determinados profissionais que possuem conhecimentos acerca das tecnologias digitais, facilitando o processo inovador nos laboratórios de tecnologia. 


\subsection{A experiência de São Paulo}

A estratégia de formação de professores do ensino médio, para uso da RE como recurso pedagógico, com base no conceito de aprendizagem cooperativa, integrada com algumas habilidades exigidas no Exame Nacional do Ensino Médio (ENEM), foi implementada em São Paulo. Essa estratégia, desenvolvida por pesquisadores da Universidade Federal do $A B C$ (UFABC), em parceria com escolas públicas da região do $A B C$, foi aplicada como um projeto de extensão. Um grupo de professores do ensino médio da rede pública participou de uma formação continuada, com duração de três meses - sem referência à carga horária - para trabalhar com projetos de robótica, a fim de aplicar essa metodologia com seus próprios alunos do ensino médio (MINAMI et al. 2018).

Participaram 22 professores, de disciplinas diferentes, tais como: Matemática, Física, Biologia, Português, História, Geografia, Sociologia e Química que trabalhavam em doze escolas. A maioria deles (73\%) não tinha conhecimento de robótica ou experiência anterior em programação de computadores. Esse projeto foi desenvolvido, tendo como premissa que a Robótica Educacional (RE), propicia um ambiente favorável à aprendizagem cooperativa. A formação de professores desenvolveu-se com base em uma metodologia de feedbacks pedagógicos, tendo como base processo de avaliação formativa (MINAMI et al. 2018).

O resumo acumulativo dos feedbacks, com base nos dados classificados no processo de avaliação formativa, efetivado durante o curso, aponta que o mais difícil é o feedback relacionado ao trabalho em equipe, demonstrando a dificuldade desse tipo de trabalho. Os feedbacks mais frequentes dizem respeito: à demonstração de competência dos alunos quanto ao que são capazes de fazer; e à eficiência no reforço do conhecimento previamente identificado, seguido do aumento do nível de aprendizagem e compreensão dos alunos, significando um bom desenvolvimento e o papel de liderança dos professores. A quase igual distribuição de outros tipos de feedback demonstrou que é extremamente poderosa, versátil e extensa essa metodologia (MINAMI et al. 2018). 


\section{A experiência da UFRN em Natal - RN}

Pesquisadores do Departamento de Engenharia de Computação e Automação, da Universidade Federal do Rio Grande do Norte (UFRN) desenvolveram uma metodologia própria para o ensino da Robótica Educacional denominada RoboEduc. Ela inclui sistemas robóticos controláveis por software, um ambiente de aprendizado para ser usado em práticas pedagógicas nas escolas e a metodologia propriamente dita com exemplos de aulas e forma de procedimentos didáticos. Esse sistema foi testado ao longo de mais de 10 anos com estudantes de várias escolas públicas do Rio Grande do Norte e demonstrou ser uma ferramenta eficiente, conforme vários trabalhos publicados (ARANIBAR et al., 2006; OLIVEIRA et al., 2017; SÁ et al. 2009; SÁ et al. 2013; SILVA, 2008).

Sua utilização na formação de professores foi realizada em 2017, quando os pesquisadores da UFRN, em parceria com o Instituto de Educação Superior Presidente Kennedy (Ifesp) e a Escola Estadual Presidente Kennedy, desenvolveram pesquisa-ação iniciada com o processo de intervenção pedagógica, por meio de um Curso de Extensão para Inovação Pedagógica em Robótica Educacional ministrado aos professores da Escola Estadual Presidente Kennedy. O fluxograma do curso, mostrado na Erro! Fonte de referência não encontrada., ilustra a proposta do curso.

O Curso de Extensão foi planejado com 60 horas, sendo 30 presenciais e outras 30 para acompanhamento dos professores no planejamento e na aplicação das aulas/oficinas, junto às turmas dos $4^{\circ}$ e $5^{\circ}$ anos. Com esse trabalho, buscou-se analisar a possibilidade de os professores inovarem em sua prática educativa após a participação em formação continuada em Robótica Educacional.

O curso foi oferecido a 12 professores; a maioria nunca havia tido contato com a robótica, tampouco ouvido falar sobre a técnica de RE, destacando a barreira que ainda existe entre a sala de aula e as novas tecnologias. O processo de treinamento ocorreu no Laboratório de Informática da Escola Kennedy com a duração de uma semana, dia inteiro - manhã e tarde - totalizando 30 horas presenciais. 
Fiqura 1 - Fluxograma do curso

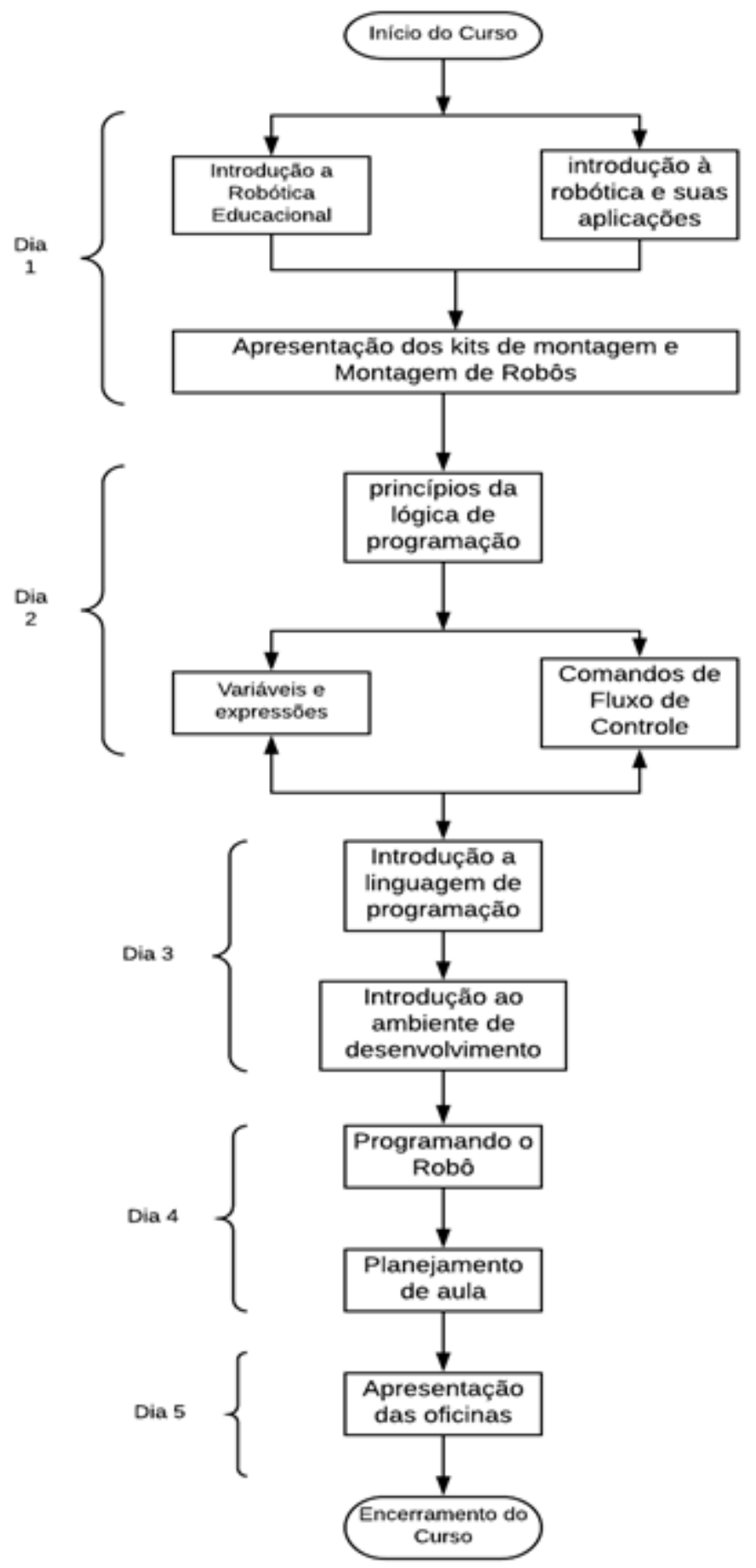

Fonte: Oliveira et al. (2017) 
O curso iniciou com a introdução dos conceitos de robótica e Robótica Educacional e suas aplicações no dia a dia com o objetivo de apresentar e familiarizar os professores com a nova metodologia. Seguindo o cronograma, no segundo dia trabalhouse com a apresentação dos fundamentos de lógica de programação, conforme Quadro 1, bem como conceitos necessários para programação dos protótipos. Este pode ser o passo mais delicado, devido à falta de familiaridade com a temática de programação. Nessa etapa, introduziram-se os conceitos alternando com exemplos práticos, tornandoos, assim, de mais fácil assimilação.

Quadro 1 - Sequência de atividades do Curso

\begin{tabular}{l|l}
\hline Seq. & Fundamentos da Lógica de Programação \\
\hline 01 & Fundamentos da lógica de programação \\
\hline 02 & Estrutura de controle de repetição \\
\hline 03 & Estrutura de controle condicional \\
\hline 04 & Operadores lógicos \\
\hline 05 & Operadores aritméticos \\
\hline 06 & Introdução ao pseudocódigo \\
\hline & Fonte: Oliveira et al. (2017)
\end{tabular}

O terceiro dia de atividades foi subdividido, começando pela introdução da linguagem e, depois, pela interface de software utilizada para programar. Para o curso em questão, utilizaram-se a linguagem R-Educ e o ambiente web W-Educ, respectivamente. Após a introdução das novas ferramentas, passou-se à parte prática do curso, com a montagem dos robôs. Os professores participam de uma breve apresentação dos kits robóticos educacionais, tratando das qualidades, funcionalidades e aplicabilidade de cada kit. Os kits, disponíveis para esse estudo de caso, são o LEGO modelo NXT, modelo EV 3 e o M-bot v 1.1, que é um kit genérico. Para a montagem, a turma foi dividida em grupos de 3 ou 4 cursistas e, em seguida, cada grupo escolheu um kit para iniciar a construção, auxiliado por um manual.

As oficinas buscaram trabalhar conteúdos que os professores aplicam em sala de aula, mostrando como planejar uma aula e como relacionar os conteúdos curriculares com a robótica educacional. Primeiro, pensam-se os conteúdos; depois, relaciona-os à 
robótica. O quarto dia iniciou-se com o desenvolvimento dos programas. Através de pequenos exercícios, os professores foram desafiados a resolver vários problemas usando conhecimento sobre programação abordado nas aulas anteriores. Durante o processo de construção dos programas, os níveis de dificuldade das atividades aumentaram à medida que os professores iam completando os desafios. A tarde foi reservada para proporcionar aos professores uma reflexão sobre o processo de desenvolvimento da prática realizada. Alguns desses exemplos estão no Quadro 2, a seguir.

Quadro 2 - Planejamento da Atividade final do curso (Aula relacionando conteúdos à Robótica)

\begin{tabular}{l|l}
\hline Conteúdos curriculares & Robótica \\
\hline Física & Sensores \\
\hline Matemática & Motores \\
\hline Português & Montagem \\
\hline História & Controle remoto \\
\hline Artes & Programação Básica \\
\hline Ciência & Fundação \\
\hline
\end{tabular}

Fonte: Oliveira et al. (2017)

Para o último dia do treinamento, foi proposto como trabalho de conclusão do curso, o preparo de uma oficina de robótica educacional sobre determinado conteúdo curricular, utilizando a metodologia da robótica educacional nos mesmos moldes do exercício praticado na véspera. Após escolher um assunto, os grupos desenvolveram uma aula com a nova metodologia, especificando o conteúdo curricular utilizado, o tópico em Robótica associado a ele e o nível ou turma a que ele seria destinando. Cada grupo fez uma apresentação, descrevendo a metodologia utilizada na aula planejada.

A pesquisa realizada acerca do processo formativo demonstrou por meio de depoimentos gravados em vídeo, a motivação dos professores cursistas quanto ao uso da Robótica Educacional, considerado desafiador e, ao mesmo tempo, prazeroso o processo de aprendizagem. De modo geral, os professores aprovaram a metodologia adotada e compareceram às oficinas para realizar as atividades planejadas para o curso. Todas as aulas foram gravadas e dispostas em um ambiente virtual em que o trabalho 
desenvolvido poderia ser revisto e os cursistas também poderiam participar de chats com os formadores.

Com o início do ano letivo, os professores foram chamados a aplicar a robótica educacional no desenvolvimento do trabalho educativo. Para que tivessem suporte no processo de inovação pedagógica, foram planejados, além das 30 horas de trabalho presencial, mais 30 horas para planejamento e desenvolvimento das aulas com os estudantes. Os professores demonstravam-se inseguros adiando o início das atividades, de forma que a realização das oficinas com os estudantes, somente, foi iniciada no segundo semestre letivo. Apenas dois dos cinco professores envolvidos, que já tinham conhecimento anterior sobre tecnologias educacionais, de fato, assumiram a proposta de trabalhar a robótica com os estudantes de suas turmas, enquanto o trabalho com as demais turmas participantes do projeto foi desenvolvido pela equipe formadora.

A experiência demonstrou que quanto mais complexa a ferramenta pedagógica, inserida no processo inovador, mais sofisticados os raciocínios requeridos, demandando maior tempo e esforço para desenvolvê-los. A programação dos robôs, por conseguinte, demandava maior tempo de estudo e prática dos professores; por outro lado, as condições de trabalho do professor não foram alteradas. Assim, alegaram não dispor de tempo para empreender estudos, tampouco para interagir no ambiente virtual, necessários à consolidação das aprendizagens e aquisição da segurança, requeridas para o processo inovador.

Embora houvesse disposição inicial, visto que compreenderam a importância da robótica como ferramenta pedagógica, nem todos os professores alcançaram os propósitos formativos, o que sinaliza a necessidade de uma maior carga horária para programação, em particular. Aqueles que possuíam maiores experiências prévias no uso das ferramentas tecnológicas, pensamento lógico-matemático, se destacaram no uso da ferramenta pedagógica. Ademais, é necessário atentar para as condições físicas, estruturais e pedagógicas em que o professor desempenha o processo de ensinoaprendizagem para que não se comprometam os resultados dos processos formativos. 


\section{Considerações finais}

Os movimentos promovidos pelo desenvolvimento tecnológico vêm pautando demandas objetivas da sociedade para com a educação, com implicações sobre as políticas públicas a ela destinadas, a exemplo das políticas de formação dos professores, para o uso das novas tecnologias. Paulatinamente, em meio a avanços e dificuldades, as políticas públicas educacionais vêm possibilitando que essas tecnologias sejam incorporadas ao contexto escolar, como ferramentas importantes para auxiliar no processo de ensino e de aprendizagem.

Entretanto, a partir deste trabalho observa-se que essas políticas ainda são insuficientes. Comprova-se isso pelo fato de que muitos profissionais da área, ainda, encontram dificuldades em inovar com o uso das tecnologias digitais, a exemplo da Robótica Educacional. Esta tecnologia se apresenta como ferramenta que pode auxiliar no processo de ensino-aprendizagem, haja vista seu potencial de articular os conteúdos curriculares, motivar a aprendizagem, desenvolver o raciocínio lógico-matemático, entre outros atributos (SILVA, 2008). Isso demanda que, entre outros quesitos, ocorram investimentos na formação dos professores que lhes permitam aproveitar o potencial dessa ferramenta.

No âmbito da rede pública de ensino, são poucas as iniciativas que têm investido no uso da robótica pedagógica nas escolas, a exemplo da experiência desenvolvida em João Pessoa, relatada neste trabalho. Assim, a maioria das experiências formativas, dirigidas aos professores da rede pública de ensino, tem sido desenvolvida por pesquisadores universitários convencidos da importância da utilização da robótica educacional nos processos de ensino e de aprendizagem.

As pesquisas-ações relatadas neste trabalho, principalmente através do projeto no Rio Grande do Norte, demonstram que, apesar do investimento realizado na compra de equipamentos e formação de professores, grande parte dos envolvidos não prosseguiu com o trabalho de inserção da Robótica Educacional em sala de aula. Essas experiências apontam que, além do processo formativo empreendido, existe a necessidade de se atentar para as experiências prévias dos professores, suas dificuldades formativas, condições de trabalho, tempo para estudos e suporte pedagógico para que adquiram 
segurança para inovar no processo pedagógico. Esses esforços são essenciais para a garantia de resultados significativos. Não atentar para eles pode comprometer os investimentos realizados na formação, impedindo a eficácia desse investimento.

\section{Referências}

ABREU, João Vilhete Viegas. Design de Dispositivos: uma Abordagem Interdisciplinar. Anais do VII Congresso Internacional Logo / I Congresso de Informática Educativa do Mercosul. Porto Alegre, UFRGS, 1995.

ALONSO, Katia Morosov. Tecnologias da informação e comunicação e formação de professores: sobre rede e escolas. Educação e Sociedade, v. 29, n. 104, 2008. p. 747-768.

ARAÚJO, C. A. Pedroso e MAFRA, J. R. e Souza. Robótica e educação: ensaios teóricos e práticas experimentais. $1 \mathrm{Ed}$. Curitiba, $\mathrm{PR}-\mathrm{CRV}, 2015$

ARANIBAR, Dennis Barrios; CASTRO, Viviane Gurgel; SANTOS, Marcela Gonçalves; ARAÚJO, Gianna Rodrigues; ROZA, Valber César Cavalcanti; NASCIMENTO, Raphaella Cristianne; SILVA, Akynara Aglaé Rodrigues Santos; GONCALVES, Luiz Marcos Garcia. RoboEduc: a software for teaching robotics to technological excluded children using LEGO prototypes. In: IEEE LATIN AMERICAN ROBOTICS SYMPOSIUM (LARS), 2006, Santiago. Anais [...]. Santiago: Universidad de Chile, 2006. p. 193-199.

PEDROSO, Carlos Alberto; MAFRA, José Ricardo e Souza. Robótica e educação: ensaios teóricos e práticas experimentais. Curitiba, PR: CRV, 2015.

AROCA, Rafael V. et al. Brazilian Robotics Olympiad: A successful paradigm for science and technology dissemination. International Journal of Advanced Robotic Systems, v. 13, n. 5, p. $1729881416658166,2016$. 
BATISTA, Esteic Janaina Santos; SILVA, Lucas Abreu da; SANTOS, Quésia de Araújo; SILVA, Camila Leite da; CASTRO JÚNIOR, Amaury Antônio. Estudo de caso sobre a implantação da robótica pedagógica em Mato Grosso do Sul. In: WORKSHOP DE ROBÓTICA EDUCACIONAL (WRE), 5. 2016, Recife, PE. Anais [...]. Porto Alegre: SBC, 2016, p. 148-154.

BRASIL. Plano de desenvolvimento da educação (PDE). 2007. Disponível em: <http://portal.mec.gov.br/arquivos/pde/default.html>. Acesso em: 10 jan. 2017.

BRASIL. Ministério da Educação, Secretaria de Educação Básica. Guia de tecnologias educacionais. Brasília: MEC, 2008. 93 p.

BRASIL. Lei $\mathbf{n}^{\circ}$ 12.056, de 13 de outubro de 2009. Acrescenta parágrafos ao art. 62 da Lei $n^{\circ}$ 9.394, de 20 de dezembro de 1996, que estabelece as diretrizes e bases da educação nacional. Disponível: <http://www.planalto.gov.br/ccivil_03/_Ato2007-2010/2009/Lei/ L12056.htm>. Acesso em: 23 mar. 2019.

BRASIL. Ministério da Educação, Secretaria de Educação Básica. Guia de tecnologias educacionais 2011/12. Brasília: MEC, 2011. 196 p.

BRASIL. Decreto n 9.099, de 18 de julho de 2017. Dispõe sobre o Programa Nacional do Livro e do Material Didático. Disponível em: <http://www.planalto.gov.br/ccivil_03/ _Ato2015-2018/2017/Decreto/D9099.htm>. Acesso em: 16 mar. 2019.

BRASIL. Fundo Nacional do Desenvolvimento da Educação, FNDE. Edital de pregão eletrônico para registro de preços $n^{\circ} 4 / 2018$ : processo administrativo $n^{\circ}$ 23034.056105/2017-88. Brasília, DF, 2018.

CARBONELL, Jaume. A aventura de inovar: a mudança na escola. Porto Alegre: Artmed, 2002.

CARVALHO, Ana Beatriz; ALVES, Thelma Panerai. Apropriação tecnológica e cultura digital: $O$ programa um computador por aluno no interior do nordeste brasileiro. Logos, v. 18, n. 1, 2011. p. 88-101.

GONÇALVES, Luiz Marcos Garcia; AROCA, Rafael Vidal; SÁ, Sarah Thomaz de Lima, GARCIA, Luciane Terra dos Santos. Anais do Workshop de Robótica Educacional (WRE), 2008-2018, Salvador, São Paulo, Fortaleza, Arequipa, São Carlos, Uberlândia, Recife, Curitiba, João Pessoa. Porto Alegre: SBC, 2008-2018. Disponível em:

<www.natalnet.br/wre201*>. Acesso em: 19 mai. 2019.

FARIAS, Isabel Maria Sabino de. Inovação, mudança e cultura docente. Brasília: Liber Livro, 2006.

GUIMARÃES, Eduardo Cortez; PERALTA, Deise Aparecida; PRADO, José Pacheco de Almeida. Uma proposta de formação de professores para o uso de robótica na escola: as possibilidades da teoria da ação comunicativa. In: WORKSHOP DE ROBÓTICA EDUCACIONAL (WRE), 5. 2014, São Carlos, SP. Anais [...]. Porto Alegre: SBC, 2014, p. 6066. 
JOÃO PESSOA. Portal da Prefeitura de João pessoa. Robótica educacional. Disponível em: <www.joaopessoa.pb.gov.br/tag/robotica-educacional/>. Acesso em: 19 out. 2017.

KENSKI, Vani Moreira. Educação e tecnologias: o novo ritmo da informação. Campinas: Papirus, 2007.

MATARIC, Maja J. et al. Introdução à robótica. São Paulo: UNESP/BLUCHER, 2014.

MINAMI, Mario; TAKAHATA, Andre Kazuo; PONCHET, André; KURASHIMA, Celso Setsuo; FANTINATO, Denis, OLIVEIRA, Tiago; BRAGA, Thays. Cooperative learning in robotics teacher formative assessment strategy integrated with brazilian national high school exam-ENEM: how digital pedagogy can build a bridge between curricula and projects. In: LATIN AMERICAN ROBOTICS SYMPOSIUM (LARS); BRAZILIAN ROBOTICS SYMPOSIUM (SBR); WORKSHOP OF ROBOTICS IN EDUCATION (WRE), 2018. João Pessoa. Anais [...]. Los Alamitos, CA: IEEE Press, 2018. p. 577-584.

MOURA, Dante Henrique; SOUSA, Andreia e Silva. Políticas de formação de professores e docência no ensino médio brasileiro. UFMA. Cadernos de Pesquisa, v. 23, 2016. p. 119-138.

OLIVEIRA, Denilton S., et al. Issues on teaching formation for educational robotics: a case study with elementary public school teachers in Natal, Brazil. In: A. A. Stupin. (Org.). Educacional Robotics: status, problems, prospects. Novosibirsk: NSPU Publishing House, 2017, v. 1, p. 24-39.

PERALTA, Deise; BRITO, Maria Claudia; PRADO, José Pacheco de Almeida; MORCELI, Gustavo. Robótica na Educação Infantil: necessidades formativas de professores. In: WORKSHOP DE ROBÓTICA EDUCACIONAL (WRE), VI, 2015. Uberlândia. Anais [...]. Porto Alegre: SBC, 2015. p. 106-111.

RIBEIRO, Fagner. A implantação da robótica educacional na Paraíba e suas repercussões no crescimento da olimpíada brasileira de robótica. In: WORKSHOP DE ROBÓTICA EDUCACIONAL, 9. João Pessoa, PB. Anais [...]. Porto Alegre: SBC, 2018, s. p.

SÁ, Sarah Thomaz de Lima. Ambiente de desenvolvimento web multiplataforma configurável para robótica educacional. 2013. Dissertação (Mestrado Engenharia Elétrica e de Computação) - Programa de Pós-Graduação em Engenharia Elétrica e Computação. Universidade Federal do Rio Grande do Norte, Natal, 2013.

SÁ, Sarah Thomaz de Lima; SILVA, Akynara Aglaé Rodrigues Santos; FERNANDES, Carla da Costa; BARROS, Renata Pitta; AZEVEDO, Samuel; BURLAMAQUI, Aquiles Medeiros Filgueira; SILVA, Alzira Ferreira da; GONCALVES, Luiz Marcos Garcia. RoboEduc: a pedagogical tool to support educational robotics. In: ASEE/IEEE FRONTIERS IN EDUCATION, 39. 2009, San Antonio, Texas. Anais [...] Los Alamitos, CA: IEEE Press, 2009. p. 1-6.

SESI, Portal da Indústria. Competições SESI: Torneio Sesi de Robótica e Festival Sesi de Robótica. 2019. Disponível em: <www.portaldaindustria.com.br/sesi>. Acesso em: 31 mar. 2019. 
SILVA, Alzira Ferreira da. RoboEduc: uma metodologia de aprendizado com robótica educacional. 2008. Tese (Doutorado em Engenharia Elétrica e de Computação) Programa de Pós-Graduação em Engenharia Elétrica e Computação. Universidade Federal do Rio Grande do Norte, Natal, 2008.

SCHLEMMER, Eliane. O trabalho do professor e as novas tecnologias. Revista Textual, Porto Alegre: Sinpro, v. 1, n. 1, nov. 2006. p. 33-42.

THURLER, Monica Gather. Inovar no interior da escola. Porto Alegre: Artmed, 2007. VYGOTSKY, Lev Semenovitch. A formação social da mente: o desenvolvimento dos processos psicológicos superiores. 7. ed. São Paulo: Martins Fontes, 2007. 